\title{
Potencial de Bacillus thuringiensis israelensis Berliner no controle de Aedes aegypti Potential of Bacillus thuringiensis israelensis Berliner for controlling Aedes aegypti
}

\author{
Ricardo Antonio Polanczyk, Marcelo de Oliveira Garcia e Sérgio Batista Alves \\ Departamento de Entomologia, Fitopatologia e Zoologia Agrícola. Escola Superior de Agricultura \\ "Luiz de Queiroz" da Universidade de São Paulo. São Paulo, SP, Brasil
}

\section{Descritores \\ Dengue, prevenção. Aedes. Controle biológico de vetores. Bacillus \\ thuringiensis. Insetos vetores. Aedes aegypti.}

\begin{abstract}
Resumo
Relata-se a importância da bactéria entomopatogênica Bacillus thuringiensis israelensis para o controle de Aedes aegypti. São abordados a utilização e potencial de $B$. thuringiensis israelensis contra o mosquito vetor da dengue. Outros aspectos são discutidos como a evolução da resistência dos insetos em relação aos inseticidas químicos e as vantagens e desvantagens do controle microbiano como estratégia de controle. É dada ênfase à importância da utilização desta bactéria no Brasil como alternativa para resolver o problema em questão sem afetar o ambiente, o homem e outros vertebrados nas áreas de risco.
\end{abstract}

\begin{abstract}
The importance of the entomopathogenic bacterium Bacillus thuringiensis israelensis in the control of Aedes aegypti is presented. The use and potential of $\mathrm{B}$. thuringiensis israelensis against the mosquito vector of dengue fever is described. Other aspects such as insect's resistance development against chemicals and advantages and constraints of using microbial control are discussed. Emphasis is given to the importance of the use of this bacterium in Brazil, which could contribute significantly to solving the mosquito problem without affecting the environment, humans and others invertebrate organisms in critical regions.
\end{abstract}

\section{INTRODUÇÃO}

A dengue é hoje a arbovirose mais importante do mundo. Aproximadamente 2,5 bilhões de pessoas encontram-se sob o risco de se infectarem, principalmente em países tropicais onde as condições climáticas (temperatura e umidade) são favoráveis a proliferação do mosquito vetor, Aedes aegypti (Tauil, ${ }^{12}$ 2002).

Os mosquitos geralmente adquirem o vírus enquanto se alimentam de sangue de pessoas infectadas. Depois de incubado por 8-10 dias, a fêmea infectada é capaz, durante a picada e a alimentação, de transmitir o vírus a indivíduos suscetíveis. As fêmeas infectadas podem transmitir o vírus para sua prole através da transmissão transovariana (via ovos), mas sua importância na transmissão do vírus para os humanos ainda não foi esclarecida (World Health Organization, ${ }^{14}$ 1997).

As características clínicas da dengue variam de acordo com a idade do paciente. Os jovens e as crianças podem apresentar febre com sintomas não específicos e os adultos podem ter síndrome febril suave ou 
sintomas clássicos da doença que são: febre alta inicial abrupta, dor de cabeça, dor atrás dos olhos, dor muscular e nas juntas e erupção cutânea. A dengue hemorrágica é uma complicação que pode levar a morte. Seus sintomas são a febre alta, fenômenos hemorrágicos, freqüentemente há a dilatação do fígado e, em casos severos, falhas na circulação. A doença normalmente começa com uma ascensão repentina da temperatura acompanhada de uma indisposição que começa com um aumento súbito da temperatura acompanhada por tremor facial e outros sintomas não específicos. A febre geralmente permanece por dois a sete dias e pode atingir $40-41^{\circ} \mathrm{C}$, podendo ser acompanhada por convulsões febris e hemorragia (World Health Organization, ${ }^{14}$ 1997).

\section{DENGUE NO BRASIL E SEU CONTROLE}

Há vários anos a dengue é um dos mais sérios problemas de saúde pública do Brasil, causando preocupação no governo e na população de várias partes do País. A principal tática adotada para o combate do mosquito é o uso maciço de produtos químicos para o controle de adultos e larvas. Entretanto, o uso intensivo de agentes químicos aumenta o custo de controle e pode afetar a saúde pública.

Atualmente, o principal problema do uso de pesticidas químicos para o controle é o desenvolvimento da resistência, resultando na redução da eficiência do produto devido à morte de todos os indivíduos suscetíveis, restando apenas os imunes ao produto. Isto foi observado nos produtos utilizados no controle de A. aegypi no Brasil (Macoris et al, ${ }^{8}$ 1999) e no exterior (World Health Organization, ${ }^{15}$ 1992). O aspecto mais sério, neste caso, é o aumento do risco ambiental e do custo de controle, porque, usualmente, é realizado um número maior de aplicações para se garantir um controle satisfatório.

Uma alternativa para se evitar este problema é a utilização de produtos com diferentes modos de ação. Estes produtos atuam em mais de um processo bioquímico e/ou fisiológico, matando o inseto de diferentes maneiras. A bactéria Bacillus thuringiensis israelensis (Bti) possui três diferentes toxinas Cry (cristal tóxico), e uma Cyt (toxina com atividade citolítica e hemolítica). Esta ação sinérgica ocorre normalmente quando são usados mais de um pesticida (Delécluse et $\mathrm{al},{ }^{4} 2000$ ). Este grande número de toxinas reduz a probabilidade do desenvolvimento da resistência (Becker, ${ }^{2}$ 2000; Regis et al, ${ }^{9} 2001$ ).

Além disso, Bti não é tóxica a humanos, uma característica muito importante, pois os agentes de controle são geralmente aplicados em áreas urbanas, com pessoas próximas à pulverização. Outro fato importante é a possibilidade da $B t i$ ser usado juntamente com produtos químicos para aumentar a eficiência do controle (Chui et al, ${ }^{3}$ 1995).

De acordo com Becker ${ }^{2}$ (2000), todos os estudos feitos após a introdução da Bti mostram que ocorreu um controle eficiente, sem que ocorressem danos ao ambiente, não havendo redução da biodiversidade dos locais tratados.

Antes de 1976, a bactéria entomopatogênica $B$. thuringiensis $(B t)$ era usada exclusivamente no controle de insetos-pragas na agricultura. Mas a descoberta de um isolado patogênico a dípteros chamado Bt israelensis (Bti) (Becker, $\left.{ }^{2} 2000\right)$ iniciou o uso dessa bactéria no controle de vetores de doenças. Desde então, estão sendo realizados inúmeros programas de seleção, visando ao isolamento de raças mosquiticidas (Delécluse et al, ${ }^{4}$ 2000).

Atualmente, a Bti é comercializada em larga escala para o controle de mosquitos e borrachudos, e um grande número de produtos eficientes estão disponíveis no mercado. A Bti foi usada em campanhas intensivas de controle realizadas nos EUA e Alemanha para o controle de pernilongos, e na África para o combate de simulídeos vetores da Oncocercose (Glare \& O'Callaghan, ${ }^{6} 2000$ ).

O uso de bactérias no controle biológico das larvas de mosquitos tem-se destacado entre as diversas estratégias que compõem os programas de manejo integrado. As principais razões para isto são as suas vantagens em relação aos inseticidas químicos. Esses produtos possuem inúmeras formulações e são usados contra diversas espécies de mosquitos, com um preço um pouco superior aos produtos tradicionalmente utilizados, mas competitivos quando considerados os custos sociais e ambientais do uso de inseticidas não seletivos em ecossistemas aquáticos (Vilarinhos et al, ${ }^{13}$ 1998).

A grande atividade inseticida deve-se às proteinases tóxicas situadas em corpos paraesporais (cristais). Eles são produzidos no segundo estágio da esporulação, durante a formação dos esporos. Após a ingestão, os cristais são dissolvidos em meio ácido ou alcalino do intestino médio e as protoxinas são liberadas, quando as protoxinas ainda não exibem atividade biológica e a ativação proteolítica necessária. As proteases do intestino desdobram as protoxinas e produzem uma proteína ativada de menor tamanho. Esta toxina tem que passar pela membrana peritrófica para ser reconhecia por receptores específicos presentes nas microvilosidades apicais do intestino médio. Após a ligação com 
o receptor, a toxina cria poros que interferem no sistema de transporte de íons pela membrana do tecido. Este processo causa lise do epitélio do intestino médio e/ou interrompe a secreção normal, baixando o $\mathrm{pH}$ do lúmem, favorecendo a germinação dos esporos que acarretará na septicemia e morte do inseto. A inibição da alimentação pode ocorrer logo após a ingestão do esporo e da toxina da $B t$, provocando a morte do inseto (Glare \& O’Callagham, $\left.{ }^{6} 2000\right)$.

Em 1983, os primeiros estudos conduzidos no Brasil avaliaram a eficiência de agentes biológicos no controle de simulídeos. Em 1986, devido aos resultados promissores iniciou-se a substituição dos organofoforados por produtos à base de Bti. Desde então, tornou-se a única tática de controle de simulídeos. Infelizmente, o uso de Bti no Brasil era baixo, embora o mercado tivesse sofrido um aumento de $1.000 \%$ entre 1994 e 1998 (Vilarinhos et al, ${ }^{13}$ 1998).

O Estado do Rio Grande do Sul foi pioneiro no uso de Bti. O programa de Controle de Simulídeos foi iniciado em 1983, com o objetivo de controlar populações resistentes de Simulium pertinax à temophos (Ruas Neto, ${ }^{11}$ 1984).

Segundo Araujo-Coutinho ${ }^{1}$ (1995), desde 1990 a Secretaria de Saúde do Estado de São Paulo vem utilizando produtos à base de Bti no programa de controle simulídeos realizados ao longo da Serra do Mar. Este nova estratégia substitui o programa iniciado em 1986 que utilizava Termophos como agente de controle.

Segundo o Serviço Regional-2 da Superintendência de Controle de Endemias da Secretaria da Saúde do Estado de São Paulo em São Vicente, * foi iniciado em maio de 2001 a utilização de inseticidas à base de Bti nos municípios de Santos, São Vicente, Cubatão, Guarujá e Praia Grande. Este bioinseticida estava sendo usado no trabalho de rotina, casa a casa, no controle dos criadouros. Entretanto, seu uso foi praticamente suspenso em setembro de 2001 devido à dificuldade de sua utilização em ralos e calhas, onde o preparado flutua e é facilmente eliminado, podendo, muitas vezes, causar o entupimento da mesma.

De acordo com Vilarinhos et al, ${ }^{13}$ (1998) dois produtos à base de Bti estão disponíveis no mercado brasileiro: Vectobac AS e Teknar. Instituições como Fundação Oswaldo Cruz, Cia. Brasileira de Antibióticos, Centro de Desenvolvimento Biotecnológico, Empresa Capixaba de Pesquisa Agropecuária, Universidade Estadual de Londrina, Universidade Esta- dual Paulista e Escola Superior de Agricultura "Luiz de Queiroz" têm produzido Bti em fermentadores com capacidade de 14 à 3.000 litros. Recentemente, a Embrapa Recursos Genéticos e Biotecnologia, que vem trabalhando em conjunto com uma companhia privada, introduziu uma novo produto à base de Bti, lançado no mercado em 2002.

De acordo com Vilarinhos et al, ${ }^{13}$ (1998) a eficiência das formulações anteriormente citadas varia de $96 \%$ a $100 \%$ até $72 \mathrm{~h}$ após a aplicação dos produtos. Com esta alta eficiência, apesar da Bti atuar somente sobre larvas, ele restringe o nível populacional do Ae. aegypti de tal modo que o inseto seja incapaz de causar epidemia. De um modo geral, em 2002, aproximadamente 360 toneladas de Bti foram usadas no combate de vetores no Brasil (Funasa, ${ }^{5}$ 2002), consumindo US\$ 2,2 milhões.

Os tabletes de Culinex ${ }^{\circledR}-B t i$ foram usados por muitos anos na Alemanha e proporcionaram excelentes resultados (Becker, $\left.{ }^{2} 2000\right)$. Esta é uma das alternativas mais promissoras de controle do Ae. aegypti (Vilarinhos et al, ${ }^{13} 1998$ e Becker, $\left.{ }^{2} 2000\right)$. Esses autores mencionaram outros aspectos positivos do uso desta tática de controle do mosquito vetores: aplicação simples, os tabletes de Bti são preparados especificamente para uso em programas de controle, e eles são facilmente distribuídos. De acordo com Regis ${ }^{10}$ (2000), a eficiência da Bti em pastilha é mantida acima de $70 \%$ até 40 dias na sombra e 25 dias no sol.

$O B t i$ foi usado também com grande sucesso no Peru, Equador e na região Amazônica do Peru (Kroeger et $a l,{ }^{7}$ 1995). Dez semanas após a aplicação, foi observada uma redução média de $60 \%$ na população de adultos. Em 1981, a campanha de erradicação de $A e$. Aegypti, realizada em Cuba, combinou a redução de criadouros do mosquito com modificações nos tanques de estoque de água com uma série de medidas legislativas, educação ambiental, controle químico e biológico (World Health Organization, ${ }^{14}$ 1997).

A $B t$ possui outras subespécies que são patogênicas a Ae. aegypti, entre as quais se pode citar: Bt aizawai, Bt amagiensis, Bt canadensis, Bt darmstadiensis, Bt entomocidus, Bt fukuakensis, Bt galleriae, Bt jagathesan, Bt kenyae, Bt kurstaki, Bt kyushuensis, Bt malaysiensis, Bt medellin, Bt morrisoni, Bt pakistani, Bt thompsoni, Bt thuringiensis, Bt tochigiensis, Bt tolworthi (Glare \& O'Callagham, ${ }^{8}$ 2000). Entretanto, essas subespécies não foram completamente estudadas para o controle de Ae. aegypti como Bti, mas representam uma fonte promissora de 
agentes de controle que eventualmente poderão usadas no futuro.

Apesar dos avanços nessa área de controle, ainda há muitos impedimentos quanto ao uso desses métodos em grande escala, considerando custos e baixo efeito residual devido principalmente à exposição direta à luz solar (inativação da toxina pela radiação ultravioleta). Além disso, de acordo com Vilarinhos et al, ${ }^{13}$ (1998) uma grande quantidade de partículas sólidas e coliformes fecais compete com os cristais da Bti, reduzindo as taxas relativas de ingestão da toxina. Ainda conforme o mesmo autor, os diferentes estádios larvais da mesma espécie geram variações na $\mathrm{CL}_{50}$ e $\mathrm{TL}_{50}$. Para otimizar o efeito da Bti pode-se utilizar este bioinseticida em combinação com organofosforado, por exemplo.
A utilização de qualquer medida de controle deve estar fortemente ligada a uma campanha de esclarecimento que informe a população da sua importância no combate a esse mosquito, evitando sua proliferação, destruindo criadouros existentes e outros potenciais.

\section{CONCLUSÃO}

A Bti representa uma alternativa eficiente no controle de Ae. aegypti. Apesar de algumas restrições, certas vantagens significativas como segurança humana, baixo desenvolvimento de resistência e a possibilidade de uso com produtos químicos tornam este entomopatógeno bastante promissor no controle biológico desse inseto. Além disso, é necessário esclarecer a população e contar com a sua ajuda no sentido de incrementar o potencial das táticas de controle.

\section{REFERÊNCIAS}

1. Araujo-Coutinho CJPC. Biological control program against simuliids in the Stade of São Paulo, Brasil. Mem Inst Oswaldo Cruz 1995;90:131-3.

2. Becker N. Bacterial control of vector-mosquitoes and black flies. In: Charles JF, Delécluse A, LeRoux CN. Entomopathogenic bacteria: from laboratory to field application. Dordrecht: Kluwer Academic Publishers; 2000. p. 383-98.

3. Chui VWD, Wong KW, Tsoi KW. Control of mosquito larvar (Diptera: Culicidae) using Bti and teflubenzuron: laboratory evaluation and semi-field test. Environ Int 1995;21:433-40.

4. Delécluse A, Pérez VJ, Berry C. Vector-active toxins: structure and diversity. In: Charles JF, Delécluse A, LeRoux CN. Entomopathogenic bacteria: from laboratory to field application. Dordrecht: Kluwer Academic Publishers; 2000. p.101-26.

5. [FUNASA] Fundação Nacional de Saúde. Roteiro para capacitação de agentes do PACS/PSF nas ações de controle da dengue. Brasilia (DF); 2002.

6. Glare TR, O'Callagham M. Bacillus thuringiensis: biology, ecology and safety. Chichester: John Wiley and Sons; 2000. p. 350.

7. Kroeger A, Horstick O, Riedl C, Kaiser A, Becker, N. The potential for malaria control with the biological larvicide Bacillus thuringiensis israelensis (Bti) in Peru and Ecuador. Acta Trop 1995;60:47-57.
8. Macoris MLG, Angrighetti MTM, Glasser CM, Garbeloti VC, Cirino VCB. Alteração da resposta de suscetibilidade de Aedes aegypti a inseticidas organofosforados em municípios do Estado de São Paulo, Brasil. Rev Saúde Pública 1999;33:521-2.

9. Regis L, Silva-Filha MH, Nielsen-LeRoux C, Charles JF. Bacteriological larvicides of dipteran disease vectors. Trends Parasitol 2001;17:377-80.

10. Regis L, Silva SB da, Melo-Santos AV. The use of bacterial larvicides in mosquito and black fly control programmes in Brazil. Mem Inst Oswaldo Cruz 2000;95:207-10.

11. Ruas Neto AL. Bacillus thuringiensis var. israelensis como alternativa no controle de simulídeos no Rio Grande do Sul. Suscetibilidade a campo. B Saúde 1984;11:21-6.

12. Tauil PL. Aspectos críticos do controle do dengue no Brasil. Cad Saúde Pública 2002;18:867-71.

13. Vilarinhos PTR, Dias JMCS, Andrade CFS, AraújoCoutinho CJPC. Uso de bactérias para o controle de culicídeos e simulídeos. In: Alves SB. Controle microbiano de insetos. Piracicaba: Fundação de Estudos Agrários Luiz de Queiroz; 1998. p. 447-80.

14. World Health Organization. Dengue haemorrhagic fever: diagnosis, treatment, prevention and control. Geneva; 1997. p. 84.

15. World Health Organization. Vector resistance to pesticides. Geneva; 1992. (WHO TRS 818). 